\title{
Potential Audibility of Three Acoustic Harassment Devices (AHDs) to Marine Mammals in Scotland, UK
}

\author{
Victoria L. G. Todd \\ Ocean Science Consulting, Spott Road, Dunbar, East Lothian, Scotland, EH42 IRR, UK. \\ School of Media Arts and Technology, Southampton Solent University, East Park Terrace, Southampton SO14 OYN, \\ $U K$.
}

\begin{abstract}
Jian Jiang
School of Media Arts and Technology, Southampton Solent University, East Park Terrace, Southampton SO14 OYN, $U K$.
\end{abstract}

\begin{abstract}
Maximilian Ruffert
School of Mathematics \& Maxwell Institute, University of Edinburgh, Edinburgh, Scotland, EH9 3FD, UK.
\end{abstract}

(Received 19 June 2018; accepted 22 November 2018)

\begin{abstract}
The modelled acoustic characteristics of three Acoustic Harassment Devices (AHDs) deployed from a fully operational salmonid fish farm, located in the Sound of Mull, Scotland (UK) are presented, using empirical seabed and water column measurements at the same location. In the Beaufort Sea state 0, the depth range of 10-50 m is the maximum range at which AHDs are potentially audible to five marine mammal species. The species present within this survey region are: the harbour porpoise, Phocoena phocoena $(99.1 \mathrm{~km})$, the killer whale, Orcinus orca $(110 \mathrm{~km})$, the bottlenose dolphin, Tursiops truncatus $(89.6 \mathrm{~km})$, the common seal, Phoca vitulina $(88 \mathrm{~km})$, and the grey seal, Halichoerus grypus $(69 \mathrm{~km})$. Consequently, within the Sound of Mull, all three AHDs could be heard throughout the water column by all species. For two models of AHDs, a behavioural disturbance level of between $140 \mathrm{~dB}-180 \mathrm{~dB}$ is observed at $1.3 \mathrm{~km}$. Habitat displacement is a cause for concern, particularly if several fish farms within a small area all deploy AHDs simultaneously. This can create a confusing sound field of varying intensity, which has potential to deter harbour porpoises from sections of their habitat.

If positioned effectively, AHDs have the potential to deter all five marine mammal species from industrial operations such as aquaculture facilities. Source levels, propagation and transmission loss measurements were highly variable and should be considered as site specific, meaning new estimates should be made for each situation.
\end{abstract}

\section{INTRODUCTION}

In the UK, impacts of both common (Phoca vitulina) and grey (Halichoerus grypus) seals on aquaculture facilities are well documented, and include: direct predation, fish injury, reduced fish growth rates, fish pen damage, loss of fish stocks and two-way genetic contamination/disease-transmission between wild and farmed fish stocks. ${ }^{12,32}$ These effects are costly to industry, so considerable effort has been put into reducing the likelihood of interactions.

Acoustic Harassment Devices (AHDs), Acoustic Deterrent Devices (ADDs), Acoustic Mitigation Devices (AMDs) or more colloquially 'seal scarers', 'seal scrammers' or 'pingers' are devices that emit aversive sounds into the marine environment. These devices focus on deterring marine mammals from approaching aquaculture facilities, fisher's lines or nets, or anthropogenic noise-emitting activities, such as pile or conductor driving during construction of bridges/offshore wind farms, or offshore drilling. Acoustic deterrent terminology was based supposedly on distinctions decided at an International Whaling Commission (IWC) meeting in Rome, ${ }^{40}$ where ADDs and pingers were considered to have lower source levels $(<185 \mathrm{~dB}$ re $1 \mu \mathrm{Pa} @ 1 \mathrm{~m})$, and AHDs, or seal scarers, higher power devices $>185 \mathrm{~dB}$ re $1 \mu \mathrm{Pa} @ 1 \mathrm{~m}$. Further guidelines stated that ADDs operate typically in the 10 - to $100-\mathrm{kHz}$ band and emit Source Levels (SL) ¡150 dB re $1 \mu \mathrm{Pa} @ 1 \mathrm{~m}$, whereas AHDs operate mainly between $5 \mathrm{kHz}$ and $30 \mathrm{kHz}$ at levels often exceeding $170 \mathrm{~dB}$ re $1 \mu \mathrm{Pa} @ 1 \mathrm{~m}$ (see Madsen, 2005). ${ }^{29,33}$ Since the term AHD has resurfaced recently, ${ }^{10,28,43,46,47,49}$ this paper referred to the original nomenclature of AHD, which reflects a number of AHDs that emit high amplitude sound across a wide range of frequencies, typically from $2-95 \mathrm{kHz}{ }^{25}$

AHDs are designed to cause discomfort and deter target species $^{19}$ but they also have potential to impact nontarget marine mammals such as harbour porpoises, Phocoena phocoena, ${ }^{18,42}$ bottlenose dolphins, Tursiops truncatus,${ }^{28}$ and killer whales, Orcinus orca ${ }^{30,46,47}$ Potential effects include damage to auditory systems, avoidance of habitats, 
behavioural alterations, and masking of biological important sounds.

On the west coast of Scotland, the use of AHDs has increased, with one study recording an increase in AHD detections from $2006(0.05 \%)$ to $2016(6.8 \%)$, with highest number of detections in $2013(12.6 \%)$, as well as substantial geographic expansion. ${ }^{9}$ This study ascertains the acoustic characteristics for three models of AHDs that were deployed from an inshore fish farm on the West coast of Scotland, UK, in the Sound of Mull, and through comparison with known marine mammal hearing ranges, determined the ranges at which AHDs are audible potentially to five marine mammal species present within the survey region: harbour porpoise, bottlenose dolphin, killer whale, grey, and common seal.

\section{METHODOLOGY}

This study formed the second stage of field trials conducted in April 2003, involving characterisation of sound levels and spectra of three models of AHD: (1) AIRMAR DB plus II, (2) Ace Aquatec silent scrammer, and (3) Terecos type DSMS4. ${ }^{26}$ At the time of that study (and to date), all devices were in use at fish farms across Scotland and elsewhere in the world. ${ }^{13,25}$ This study expands upon Lepper et al., ${ }^{26}$ by using additional oceanographic measurements taken at the location during those trials to strengthen modelling predictions of AHD signals across the Sound of Mull channel. While the study was conducted over 15 years ago, publication was delayed inter alia due to the sudden death of one of the field engineers (David Goodson). However, AHD technology in use today has not changed significantly (and in the case of AIRMAR and Terecos, not changed at all), the original fish farm is still in existence, and environmental variables measured are still within valid context for such trials, so data collected are still relevant now.

\subsection{Study Area}

During the Lepper et al. ${ }^{26}$ study, field measurements of conductivity, temperature and depth (CTD), and seabed type was obtained over two days from April 4-5 in 2003. These measurements were obtained from a fully-operational salmonid fish farm, located $0.25 \mathrm{~km}$ from shore, in Fishnish Bay, Sound of Mull, Scotland, UK (fish farm A, Fig. 1). The mean water depth was $30 \mathrm{~m}$. A number of other commercial salmon farms were also situated in the region, the nearest being fish farm B (Fig. 1).

\subsection{CTD Casting and Grab Sampling}

Eleven boat transect, running radially from as near to the AHD sound source as possible, to various far-field positions were undertaken (Fig. 1), from the Length Over All (LOA) $10.4 \mathrm{~m}$ general research vessel, RV Seol Mara. Transects ranged from $0.6-1.6 \mathrm{~km}$. At the start of each transect, a CTD profile (SeaBird 19; sample rate $2 \mathrm{~Hz}$ ), and two replicate $0.045 \mathrm{~m}^{2}$ Van Veen grab samples were taken. Ad hoc off-transect grabs were also taken to the southeast of the farm. Careful descriptions were made of the sediment samples' colour, texture, smell and appearance. Along each transect, seven equally spaced depth readings (in metres) and a description of the sea bed using the vessel's echosounder (Simrad EL Echo Sounder) were also carried out.

\subsection{Acoustic Modelling}

Acoustic modelling was performed initially to investigate ranges at which harbour porpoises, bottlenose dolphins, killer whales, common/harbour, and grey seals could potentially hear AHD signals. Hearing ranges for all species were sourced from underwater audiograms reported in the literature (Tab. 1).

Two extreme conditions, sea state 0 and sea state 6 , were investigated to give a range of these distances. Sound transmission loss/propagation loss under sea state 0 was estimated by using a cylindrical spreading model (for long distance), which can be expressed as Eq. (1):

$$
T L=10 \log R+10 \log H+\alpha R ;
$$

where $T L$ was transmission loss, $R$ was the distance to source, $H$ was the average sea depth ( $30 \mathrm{~m}$ in this study), and $\alpha$ is absorption coefficient, as per method described in Kastelein et al. $^{22}$

For sea state 6, a spherical spreading model (for short distance) was used to investigate the transmission loss (Eq. (2)). This is because, for sea state 6 , ambient noise was considerably higher and corresponding SNR was lower than at sea state 0 . Consequently, AHD signals propagated shorter distances at higher sea states and a spherical spreading model was used:

$$
T L=20 \log R+\alpha R
$$

Here $\alpha(\mathrm{dB} / \mathrm{km})$ was frequency dependent and was estimated by using Thorpe's expression (Eq. (3)):

$$
\alpha(f)=\left\{\begin{array}{cc}
0.11 \frac{f^{2}}{1+f^{2}}+44 \frac{f^{2}}{4200+f} & \\
+2.75 \times 10^{-4} f^{2}+0.003 & f>0.4 \\
0.002+0.11 \frac{f}{1+f}+0.011 f & f<0.4
\end{array} ;\right.
$$

where $f$ was the frequency in $\mathrm{kHz}$. The sound considered here was within a very narrow band or just for one AHD frequency. Therefore, if the formula depends on frequency, that particular frequency will be used.

Distance at which sound can be heard was then obtained by solving Eq. (3):

$$
S L-T L(R)-\max (N L, D T)=0 ;
$$

where, $S L$ was the source level obtained from the experiment, $T L$ was distance dependent transmission loss, which was estimated by Eq. (1) and (2). DT was the detection hearing thresholds, ${ }^{31} N L$ was ambient noise level, and ' $\max (N L, D T)$ ' returned the larger value after comparing $N L$ and $D T$ at any particular frequency. Similar models were used by Kastelein et al., ${ }^{22}$ with the exception of the $N L$, which was estimated here by using a more comprehensive model that summed the 


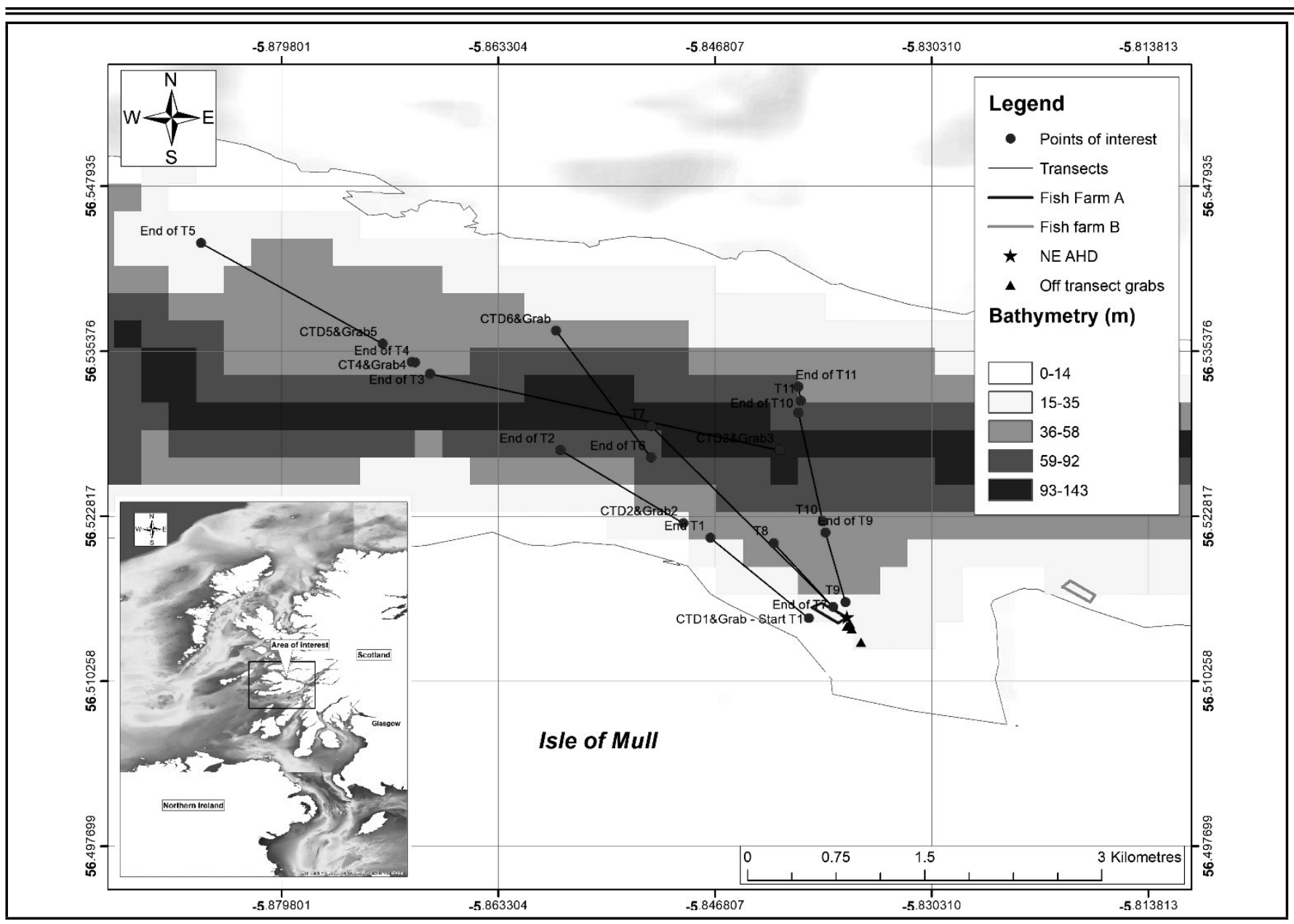

Figure 1. Location of study area including bathymetric/oceanographic boat transects.

Table 1. Marine mammal hearing ranges - excerpt modified from Table 1.3 in. reference ${ }^{20} H P=$ harbour porpoise; $B D=$ bottlenose dolphin; $K W=$ killer whale; $C S=$ common seal; $G S=$ grey seal; $M=$ Male; $F=$ Female; $U=$ unknown sex; $A B R=$ Auditory Brainstem Response; $A E P=$ Auditory Evoked Potential; $B=$ Behavioural audiogram; $p-p=$ peak-to-peak; $r m s=$ root mean square.

\begin{tabular}{||c|c|c|c||}
\hline $\begin{array}{c}\text { Species \& } \\
\text { audiogram type }\end{array}$ & $\begin{array}{c}\text { Range of best hearing } \\
(10 \mathrm{~dB} \text { from max; } \mathrm{kHz})\end{array}$ & $\begin{array}{c}\text { Frequency of min } \\
\text { hearing threshold } \\
(\mathrm{kHz})\end{array}$ & $\begin{array}{c}\text { Min hearing threshold } \\
(\mathrm{dB} \text { re 1 } \mu \mathrm{Pa})\end{array}$ \\
\hline$H P--M ; B$ & $16-140$ & 100 & 44 \\
$H P--U ; B$ & - & 150 & 30 \\
$H P--U ; A B R$ & $130-140$ & 130 & 9 \\
$H P--U ; A E P$ & - & 125 & 38.9 (mean $)$ \\
\hline$B D--M \& F ; A E P$ & $16-32$ & 20 & 79.7 (mean) \\
$B D--M \& F ; A E P$ & $10-50$ & 20 & $34 \mathrm{rms}$ \\
\hline$K W--F ; B$ & - & 20 & $37 \mathrm{p}-\mathrm{p}$ \\
\hline$K W--F ; A E P$ & $20-45$ & 1 & $54 \mathrm{rms}$ \\
\hline$C S--F ; B$ & $0.5-40$ & $20-25$ & $61-62$ \\
\hline$G S--F ; A B R$ & $20-30$ & \multicolumn{2}{|c}{} \\
\hline
\end{tabular}

noise components from turbulence $(N t)$, from shipping $(N s)$, from wind $(N w)$ and thermal noise $(N t h) .6,16,27,50,52$ Detailed expressions of these noise components (in $\mathrm{dB}$ ) are presented in Eq. (4), (5), (6), and (7):

$$
N t(f)=17-30 \log (f)
$$

$$
\begin{aligned}
& N s(f)=10+20(s-0.5)+26 \log (f)-60 \log (f+0.03) ; \\
& N w(f)=50+7.5 w^{0.5}+20 \log (f)-40 \log (f+0.4)
\end{aligned}
$$

$$
N \operatorname{th}(f)=-15+20 \log (f)
$$

where, $f$ was frequency in $\mathrm{kHz}, s$ was the shipping factor, which was given as 0.5 here, and $w$ was the wind speed which is $0.2 \mathrm{~ms}^{-1}$ for sea state 0 and $20.7 \mathrm{~ms}^{-1}$ for sea state 6 .

To summarise, assumptions and parameters used in the model included:

- Sea state 0 and 6 were considered respectively;

- Modelling at sea state 0 used a cylindrical spreading model and modelling at sea state 6 used a spherical spreading model;

- An average shipping factor, 0.5, was used here; and, 
- Wind speeds were $0.2 \mathrm{~ms}^{-1}$ for sea state 0 , and $20.7 \mathrm{~ms}^{-1}$ for sea state 6.

Based on empirical CTD/seabed data from the location, advanced acoustic modelling was also carried out by using the Bellhop two-dimensional ray tracing-based underwater acoustic model to predict sound propagation and transmission loss across the channel. $8,14,37,38,52$ This is a traditional beam tracing model for predicting acoustic pressure fields in ocean environments and is most suited to short range, high frequency scenarios. The Bellhop model was written by Mike Porter at HSL Research. Alec Duncan from the Centre for Marine Science and Technology at Curtin University wrote the AcTUP User Interface for the program. It is likely that, in most cases, the prevailing geography (headlands, islands) will limit AHD noise acoustic propagation to a few kilometres.

To use the Bellhop model, sound profiles of the considered area must be known. These profiles were obtained from the empirical CTD data measured at the fish farm and surrounding area.

Parameters for environmental modelling are relatively straightforward to define, as sound speed profiles can be derived from CTD data and sea state can be derived from mean wind speeds. For the seabed, only surficial sediment data was necessary at AHD frequencies of operation. Since sediment penetration at these wavelengths was limited and does not contribute to down range re-emergence back into the water column. Bottom sediment type was used to simply define a loss vs. grazing angle methodology which is commonly used in ray/beam models.

\section{RESULTS}

Sound characteristics of the AIRMAR, Ace Aquatec, and Terecos were characterised in the first phase of the study by Lepper et al. ${ }^{26}$ estimated hearing ranges and modelled signal propagation characteristics across the Sound of Mull channel are based on those values.

\subsection{Hearing Ranges}

Ranges at which marine mammal species could potentially hear AHDs were estimated using the acoustic propagation models that were introduced in previous sections. Figure 2 shows source level of the AIRMAR, harbour porpoise hearing threshold, and ambient noise level under sea states 0 and 6. The porpoise hearing threshold lies mostly between the two ambient noise levels at both sea states, which indicates that under clement weather conditions, the distance of audibility is more dependent on the harbour porpoise hearing threshold. However, as weather deteriorates, the harbour porpoise hearing threshold depends more on ambient noise level.

Figure 3 shows potential harbour porpoise AIRMAR hearing ranges under sea state 0 and 6 conditions estimated at frequencies from 0 to $160 \mathrm{kHz}$. The most effective frequency is around AIRMAR operational frequency which is $\sim 10 \mathrm{kHz}$. Potential audible range is ca. $63.5 \mathrm{~km}$ for sea state 0 and ca. $32 \mathrm{~km}$ for sea state 6 .

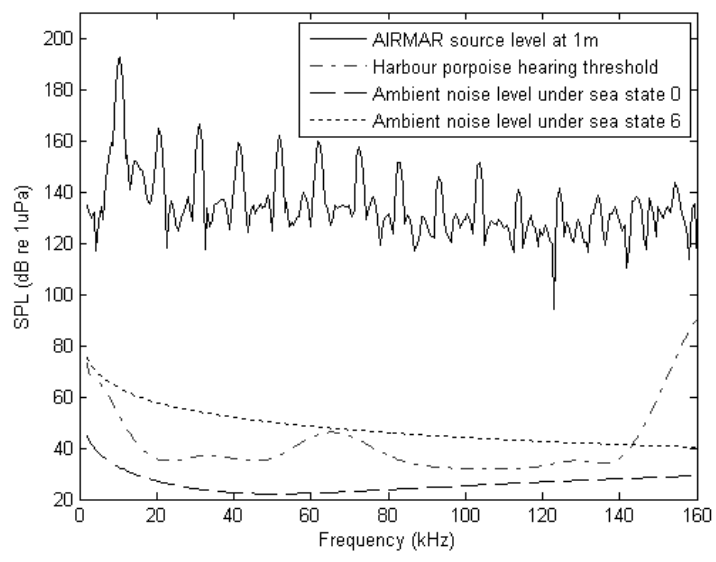

Figure 2. Sound pressure level of AIRMAR at $1 \mathrm{~m}$ from the source (solid line), Hearing threshold of harbour porpoise (dash-dot line), ambient noise levels under sea state 0 (dashed line) and sea state 6 (dotted line).

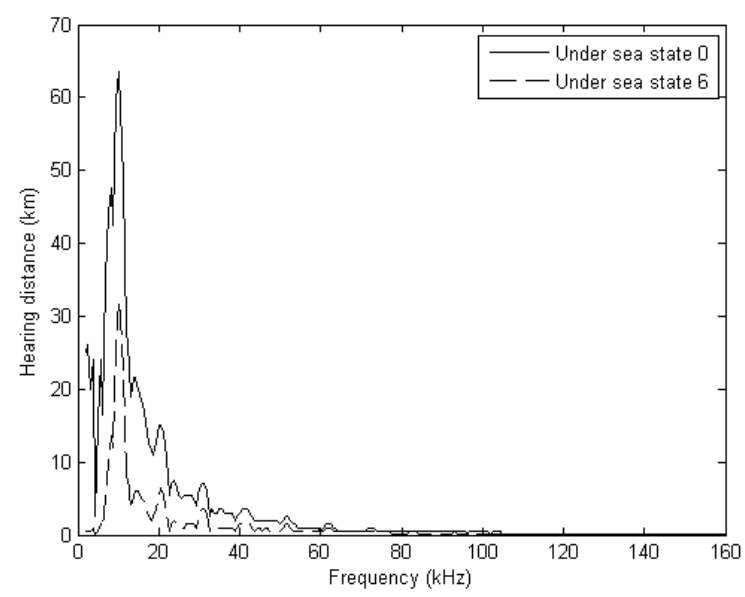

Figure 3. Harbour porpoise potential audible range of AIRMAR signal under sea state 0 (solid line) and sea state 6 (dashed line).

Theoretical ranges of audibility for remaining species and AHDs are shown in Tab. 2.

From measurements made by Lepper et al., ${ }^{26}$ all three AHDs could potentially reach source levels $>145 \mathrm{~dB}$ re $1 \mathrm{~dB} \mu \mathrm{Pa}$ at their working frequencies, varying from $5 \mathrm{kHz}$ to $70 \mathrm{kHz}$. The loudest frequency is at $\sim 10 \mathrm{kHz}$, where two AHDs reach a source level $>190 \mathrm{~dB}$ re $1 \mu \mathrm{Pa}$.

In order to calculate sound speed profiles, five boat-based CTD measurement positions were taken across the Sound of Mull channel at $-0.2135 \mathrm{~km}, 0 \mathrm{~km}, 0.3778 \mathrm{~km}, 0.7419 \mathrm{~km}$ and $1.987 \mathrm{~km}$ away from the source respectively, as shown in Fig. 4. Negative $r$ indicates the other side of source. The last position $(r=2.957 \mathrm{~m})$ is not measured in practice, as its sound profile is a repeat of the first position where $r=-0.2135 \mathrm{~m}$, because they have similar depths. Depth across the channel varied from 10-50 m. According to Van Veen grab samples taken during CTD casts, the bottom boundary is comprised of sand and clay, with an estimated speed of sound of $1800 \mathrm{~ms}^{-1}$ (Hamilton and Bachman, 1982).

Simulation was carried out by placing a theoretical omni- 
Table 2. Potential audible range $(\mathrm{km})$ for five marine mammal species to three AHDs.

\begin{tabular}{||c|c|c|c|c|c|c||}
\hline \hline & \multicolumn{3}{|c|}{ Sea state 0 } & \multicolumn{3}{c||}{ Sea state 6 } \\
\cline { 2 - 7 } & AIRMAR & Ace & Terecos & AIRMAR & Ace & Terecos \\
\hline Harbour porpoise & 63.5 & 68 & 99.1 & 32 & 33.5 & 37 \\
Killer whale & 78 & 70 & 110 & 30 & 33.5 & 37 \\
Bottlenose dolphin & 58 & 63 & 89.6 & 31 & 33.5 & 37 \\
Common seal & 55.6 & 60 & 88 & 32 & 33 & 34 \\
Grey seal & 42 & 46 & 69 & 21 & 22 & 21.5 \\
\hline
\end{tabular}

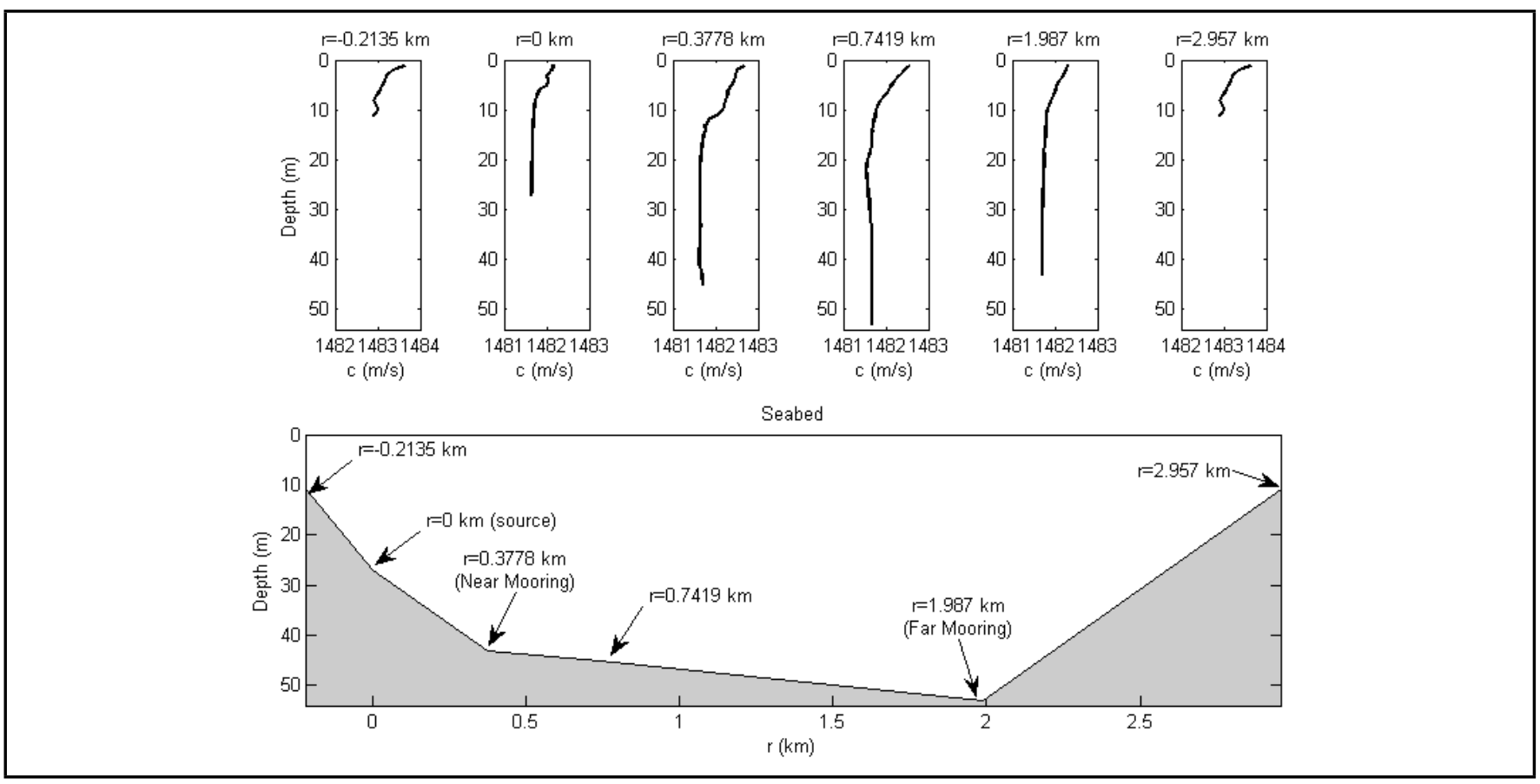

Figure 4. Top panels show CTD-derived sound speed profiles (c) across the channel, with positions or ranges (r) of $-0.2135 \mathrm{~km}, 0 \mathrm{~km}, 0.3778 \mathrm{~km}, 0.7419 \mathrm{~km}$ and $1.987 \mathrm{~km}$ away from the source respectively. Bottom panel shows positioning.

directional source $8 \mathrm{~m}$ below the surface, the same depth as the AHD devices were operated in the field. Transmission loss $(T L)$ of a $10 \mathrm{kHz}$ signal is shown in Fig. 5. Transmission loss varies from $10 \mathrm{~dB}$ to $60 \mathrm{~dB}$. While there are small variations caused by reflection and wave bending, average $T L$ increases with distance. Assuming a sound level of $190 \mathrm{~dB}$, by averaging $T L$ along depth, a result of SPL against horizontal distance to the source $(r)$, is showed in Fig. 6. The hearing thresholds of multiple species known to occur in the Sound of Mull are also marked in Fig. 6. Assuming AHD sound spreads spherically initially and then cylindrically, the AHDs in this study will be heard by marine mammals throughout the water column in the sound of Mull. If they were in open water, AHD noise could be heard potentially by marine mammals out to hundreds of $\mathrm{km}$. For Ace Aquatec and AIRMAR, sounds could potentially reach a behavioural disturbance level (140-180 dB) within a radius of $1.3 \mathrm{~km}$.

\section{DISCUSSION}

The exact effects of anthropogenic (man-made) sound on marine mammals are unknown, but reviews $1,35,41,44,51$ highlight that increased background noise and certain sound sources might impact marine mammals in several ways: (1) masking of important sounds (including communication sig- nals, echolocation, sounds associated with finding prey or avoiding predators, and human threats such as shipping); (2) alterations in behaviour (including displacement from feeding/breeding/migration habitat); (3) hearing loss (temporary or permanent); (4) chronic stress; and, (5) indirect effects including displacement of prey species. Moreover, in addition to myriad possible effects from noise exposure that can all interact together, it is important to consider the potential cumulative effects of multiple anthropogenic stressors. ${ }^{51}$

Harbour porpoises have a hearing range between 32$140 \mathrm{kHz}$, with a peak hearing at $120-130 \mathrm{kHz} .^{20,23}$ Consequently, porpoises are sensitive to all three AHD working frequencies, and are estimated to be able to detect AHDs within the study area between $63.5 \mathrm{~km}$ (AIRMAR) and $99.1 \mathrm{~km}$ (Terecos) away. The majority of research into harbour porpoise interactions with AHDs report behavioural changes and exclusion from habitat at varying levels (Culik et al., 2001; Carlström et al., 2002; Johnston, 2002; Gonener and Bilgin, 2009; Brandt et al., 2010; Brandt et al., 2012; Brandt et al., 2013). ${ }^{2-5,7,11,18}$ As expected, strength of marine mammal reaction to AHDs decreases with increasing distance. Olesiuk et $\mathrm{al}^{36}$ found that detections decreased to $0.2 \%$ of the control period at a distance of $200 \mathrm{~m}$ from an AIRMAR, and to $8.1 \%$ of control periods at $3.5 \mathrm{~km}$ of the device. Johnston ${ }^{18}$ noted that 


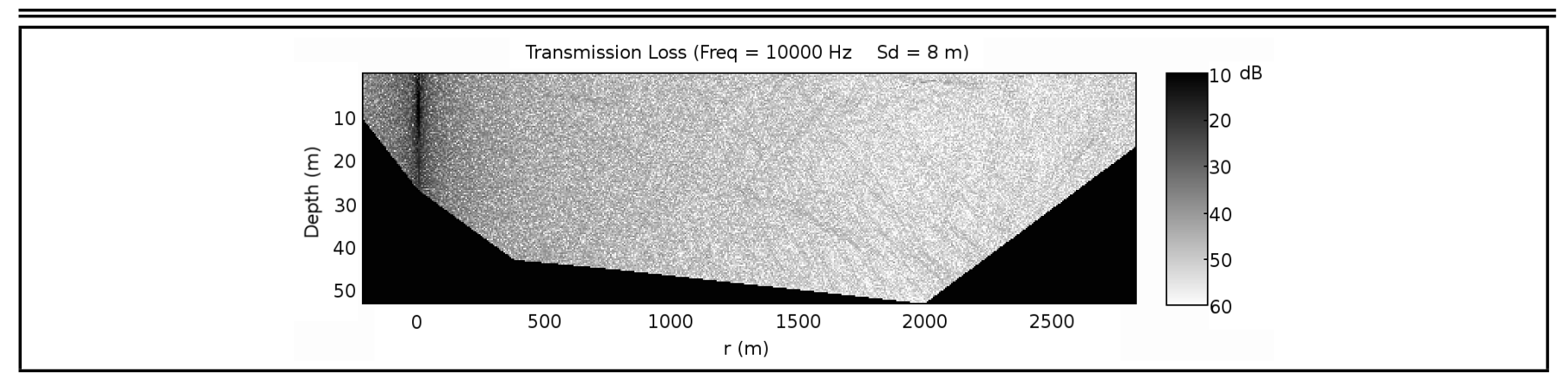

Figure 5. Simulation of transmission loss for $10 \mathrm{kHz}$ signal across the channel at various ranges $(r)$ from the source. $S d=$ source depth.

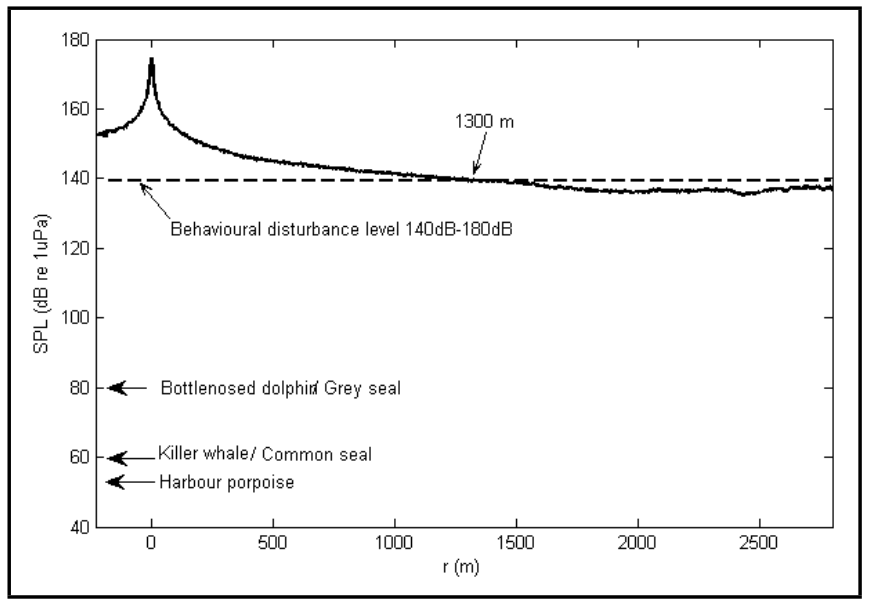

Figure 6. Averaging Sound Pressure Level (SPL) across the Sound of Mull channel with AHD source level at $190 \mathrm{~dB}$. Hearing thresholds of harbour porpoise, killer whale, bottlenose dolphin, common seal, and grey seal are marked out by arrows. Threshold of potential behavioural disturbance level (140 dB from Southall et al. ${ }^{33}$ ) is marked as dashed line.

harbour porpoises remained ca. $650 \mathrm{~m}$ away from an AHD in the Bay of Fundy. These results, however, are not conclusive, with other studies reporting apparent tolerance to AHDs, and possible habituation. ${ }^{34}$ More recent work by Kastelein et al. ${ }^{21}$ on an Ace Aquatec AHD, showed changes in harbour porpoise surfacing and swimming patterns. With the exception of more recent studies that involve trials on Lofitech seal scarers, ${ }^{2-4,21}$ which were not available during these field trials, all research trials have involved the AIRMAR model. Since acoustic signals from both Terecos and Ace Aquatec are considerably different to AIRMAR, the prediction of behavioural impacts is problematic. In terms of known and quantified maximum ranges of AHD-effect on porpoises, the farthest reported distance that a behavioural effect of a Lofitech was of $7.5 \mathrm{~km} .{ }^{4}$ In this case, Brandt et al. ${ }^{4}$ recorded a significant reduction in harbour porpoise detection rate at their farthest acoustic monitoring location of $7.5 \mathrm{~km}$; consequently, it is feasible under certain oceanographic/bathymetric conditions, especially with a neophyte porpoise population, that a response would be detected at even greater distances.

Limited research has been conducted on bottlenose dolphin responses to active AHDs. López and Mariño (2011) monitored bottlenose dolphin presence in a fish farm for 20 weeks in Sardinia, Italy. An AHD (ICA S.L, (Ingenieria y Ciencia Ambiental S.L, Madrid, Spain), with a source level of $194 \mathrm{~dB}$ re $1 \mu \mathrm{Pa} @ 1 \mathrm{~m}$ and fundamental frequency of $6.2-9.8 \mathrm{kHz}$, was deployed at $4 \mathrm{~m}$ depth from one of the floating cages. No significant difference in bottlenose dolphin presence, range from AHD, group size or time spent in the farm was observed between active and inactive periods.

Morton and Symonds (2002) studied killer whale presence in relation to AHDs in the Johnstone Strait and Broughton Archipelago, British Columbia, Canada. In 1993, four AIRMARs, with source levels of $194 \mathrm{~dB}$ re $1 \mu \mathrm{Pa} @ 1 \mathrm{~m}$ at $10 \mathrm{kHz}$, were deployed within the Archipelago. Prior to AHD installation, killer whale presence was stable in both areas, but once AHDs were activated, killer whale presence declined significantly in Broughton Archipelago, and increased in Johnstone Strait. Presence returned to baseline levels in 1999 once the AHDs were removed. ${ }^{30}$ This suggests killer whales may avoid active AHDs, but other studies show that avoidance effects may be short-lived. Tixier et al. ${ }^{46}$ for example deployed an AHD with source levels of $195 \mathrm{~dB}$ re $1 \mu \mathrm{Pa} @ 1 \mathrm{~m}$ at $6.5 \mathrm{kHz}$ from a Patagonian toothfish longline, located off the Crozet Islands. Killer whales avoided the AHD initially, moving up to $700 \mathrm{~m}$ away, but following 3-7 exposures individuals were back within 30-300 $\mathrm{m}$ of the vessel, depredating longlines again.

Common/harbour seals are one of the target species for AHDs in the Sound of Mull and have a range of hearing between $0.5-40 \mathrm{kHz}^{24}$ As a result, they are sensitive to working frequencies. To date, published studies on the effects of AHDs on seals are inconsistent and inconclusive. For example, Yurk and Trites ${ }^{53}$ reported that harbour seal depredation was reduced significantly by the presence of an AIRMAR in British Columbia, Canada, but Jacobs and Terhune ${ }^{17}$ found the same species and AHD model showed no change in behaviour in when deployed for eight months in the Bay of Fundy, Canada.

Ranges at which AHDs are potentially audible for marine mammal species is likely to be site specific and, due to differences between source levels and the frequency spectra of models, vary with local propagation conditions, bathymetry, and background noise level. All measurements for this study were taken during sea states of $\leq 2$, ensuring optimum working conditions. However, as the sea state increases, attenuation rate also increases and aeration effects are more prominent, which will cause sound distortion and reduce signal efficiency. ${ }^{39}$ Moreover, if AHDs are used around fish farms or areas with multiple manmade structures such as cages and nets then sound transmission may be blocked and reflected in alternate directions, making the distance travelled less easy to 
predict. $^{45}$ The hearing ranges for marine mammals, which are based on audiograms taken in captivity under controlled and quiet conditions, in reality, background/ambient noise will mask AHD signals to a certain extent and reduce ranges over which AHDs will be heard. Consequently, ranges presented in this study are considered to be conservative.

\section{CONCLUSIONS}

If positioned effectively, it is clear that all three AHD devices have potential to deter all five marine mammal species examined from industrial operations, such as pile-driving and from aquaculture facilities. Source levels, propagation and transmission loss measurements are highly variable and should be considered as site specific, meaning new estimates should be made for each individual situation.

Non-target AHD-induced marine mammal habitat displacement is of concern for the species in this study, particularly if several fish farms within a small area all deploy AHDs simultaneously. This can create a confusing sound field of varying intensity, which has potential to deter harbour porpoises from multiple sections of their habitat. ${ }^{13,34}$ Additionally, if AHDs are deployed in geographically constrained environments, where access routes are limited such as rivers and estuaries (or in this case the narrow channel of the Sound of Mull), then access to key foraging areas could be prevented. ${ }^{5}$ Within the Sound of Mull, all three AHDs can be heard throughout. However, for the Ace Aquatec and AIRMAR, a behavioural disturbance level of between $140 \mathrm{~dB}-180 \mathrm{~dB}$ (Yang et al., 2009) can be observed at $1.3 \mathrm{~km}$.

\section{ACKNOWLEDGEMENTS}

This paper is dedicated to the late David Goodson, who participated in the original field trials. Thanks to Elizabeth Seely (The Whale Museum, Friday Harbor, Washington, USA) for assistance with GIS, and to Dean Waters (University of York, UK), Jane Warley (OSC-UK), Melanie Orr (OSC-NZ), Cara Hoggan (OSC-UK), and Laura Williamson (OSC-UK) for comments to previous drafts. Thanks to Paul Lepper (NewLeap Ltd.) for participation in the original field trials, and to Kenny Black and Martin Sayer (both of the Scottish Association for Marine Science) for guidance, support (and humour!) throughout the original trials.

\section{REFERENCES}

1 Andersen, S. M., Teilmann, J., Dietz, R., Schmidt, N. M., and Miller, L. A. Behavioural responses of harbour seals to human-induced disturbances, Aquatic Conservation: Marine and Freshwater Ecosystems, 22, 113-121, (2012). https://dx.doi.org/10.1002/aqc.1244

2 Brandt, M. J., Diederichs, A., Höschle, C., Wollhein, L., and Nehls, G. The use of seal scarers during offshore pile driving - an effective mitigation measure for harbour porpoises (Phocoena phocoena)?, 24th Annual Conference of the European Cetacean society, Stralsund, Germany, 1, (2010).

3 Brandt, M. J., Hoschle, C., Diederichs, A., Betke, K., Matuschek, R., and Nehls, G. Seal scarers as a tool to deter harbour porpoises from offshore construction sites, Marine Ecology Progress Series, 475, 291-302, (2013). https://dx.doi.org/10.3354/meps 10100

4 Brandt, M. J., Höschle, C., Diederichs, A., Betke, K., Matuschek, R., Witte, S., and Nehls, G. Effectiveness of a sealscarer in deterring harbour porpoises (Phocoena phocoena) and its application as a mitigation measure during offshore pile driving, BioConsult SH, 72, (2012).

5 Carlström, J., Berggren, P., Dinnétz, F., and Börjesson, P. A field experiment using acoustic alarms (pingers) to reduce harbour porpoise by-catch in bottom-set gillnets, ICES Journal of Marine Science, 59, 816-824, (2002). https://dx.doi.org/10.1006/jmsc.2002.1214

6 Coates, R. F. W. Underwater Acoustic Systems, John Wiley \& Sons Inc, 188, (1990).

7 Culik, B. M., Koschinski, S., Tregenza, N., and Ellis, G. M. Reactions of harbor porpoises Phocoena phocoena and herring Clupea harengus to acoustic alarms, Marine Ecology Progress Series, 211, 255-260, (2001). https://dx.doi.org/10.3354/meps211255

8 Dong, D, and Dong, D. Bellhop - A modeling approach to sound propagation in the ocean. Department of Electronics and Telecommunication, Norwegian University of Science and Technology, NO-7491 Trondheim, Norway, 4, (2014).

9 Findlay, C. R., Ripple, H. D., Coomber, F., Froud, K., Harries, O., van Geel, N. C. F., Calderan, S. V., Benjamins, S., Risch, D., and Wilson, B. Mapping widespread and increasing underwater noise pollution from acoustic deterrent devices, Marine Pollution Bulletin, 135, 1042-1050, (2018). https://dx.doi.org/10.1016/j.marpolbul.2018.08.042

10 Fjalling, A., Wahlberg, M., and Westerberg, H. Acoustic harassment devices reduce seal interaction in the Baltic salmon-trap, net fishery, ICES Journal of Marine Science, 63, 1751-1758, (2006). https://dx.doi.org/10.1016/j.icesjms.2006.06.015

11 Gonener, S., and Bilgin, S. The effect of pingers on harbour porpoise, Phocoena phocoena bycatch and fishing effort in the turbot gill net fishery in the Turkish Black Sea Coast, Turkish Journal of Fisheries and Aquatic Sciences, 9, 151157, (2009). https://dx.doi.org/10.4194/trjfas.2009.0205

12 Gordon, J., and Northridge, S. P. Potential impacts of acoustic deterrent devices on Scottish marine wildlife, Scottish Natural Heritage Commissioned Report F01AA404, 63, (2002). 
13 Götz, T., and Janik, V. M. Acoustic deterrent devices to prevent pinniped depredation: efficiency, conservation concerns and possible solutions, $M a$ rine Ecology Progress Series, 492, 285-302, (2013). https://dx.doi.org/10.3354/meps 10482

14 Gul, S. S., Zaidi, H., Khan, R., and Wala, A. B. Underwater acoustic channel modeling using BELLHOP ray tracing method, 14th International Bhurban Conference on Applied Sciences and Technology (IBCAST), Islamabad, 665-670, (2017). https://dx.doi.org/10.1109/IBCAST.2017.7868122

15 Hamilton, E. L., and Bachman, R. T. Sound velocity and related properties of marine sediments, Journal of the Acoustical Society of America, 72, 1891-1904, (1982). https://dx.doi.org/10.1121/1.388539

16 Harris, A., and Zorzi, M. Modelling the underwater acoustic channel in ns2, 2nd international conference on Performance evaluation methodologies and tools, Nantes, France, 8, (2007).

17 Jacobs, S. R., and Terhune, J. M. The effectiveness of acoustic harassment devices in the Bay of Fundy, Canada: seal reactions and a noise exposure model, Aquatic Mammals, 28, 147-158, (2002).

18 Johnston, D. W. The effect of acoustic harassment devices on harbour porpoises (Phocoena phocoena) in the Bay of Fundy, Canada, Biological Conservation, 108, 113-118. (2002). https://dx.doi.org/10.1016/S0006-3207(02)00099$\mathrm{X}$

19 Johnston, D. W., and Woodley, T. H. A survey of acoustic harassment device (AHD) use in the Bay of Fundy, NB, Canada, Aquatic Mammals, 24, 51-61, (1998).

20 Kastelein, R. A., Bunskoek, P., Hagedoorn, M., Whitlow, W. L. A., and de Haan, D. Audiogram of a harbor porpoise (Phocoena phocoena) measured with narrow-band frequency-modulated signals, Journal of the Acoustical Society of America, 112, 334-344. (2002). https://dx.doi.org/10.1121/1.1480835

21 Kastelein, R. A., Hoek, L., Gransier, R., de Jong, C. A., Terhune, J. M., and Jennings, N. Hearing thresholds of a harbor porpoise (Phocoena phocoena) for playbacks of seal scarer signals, and effects of the signals on behavior, Hydrobiologia, 756, 89-103, (2015). https://dx.doi.org/10.1007/s10750-014-2035-x

22 Kastelein, R. A., Hoek, L., Jennings, N., de Jong, C. A. F., Terhune, J. M., and Dieleman, M. Acoustic mitigation devices (AMDs) to deter marine mammals from piledriving areas at sea: Audibility and behavioural response of a harbour porpoise and harbour seals COWRIE, Ref: SEAMAMD-09, Technical Report, 31st July, (2010).

23 Kastelein, R. A., Verboom, W. C., Jennings, N., de Haan, D., and van der Heul, S. The influence of 70 and $120 \mathrm{kHz}$ tonal signals on the behavior of harbor porpoises (Phocoena phocoena) in a floating pen, Marine Environmental Research, 66, 319-26, (2008). https://dx.doi.org/10.1016/j.marenvres.2008.05.005

24 Kastelein, R. A., Wensveen, P., Hoek, L., and Terhune, J. M. Underwater hearing sensitivity of harbor seals (Phoca vitulina) for narrow noise bands between 0.2 and $80 \mathrm{kHz}$, Journal of the Acoustical Society of America, 126, 476483, (2009). https://dx.doi.org/10.1121/1.3132522

25 Lepper, P. A., Gordon, J., Booth, C., Theobald, P., Robinson, S. P., Northridge, S., and Wang, L. Establishing the sensitivity of cetaceans and seals to acoustic deterrent devices in Scotland, Scottish Natural Heritage Commissioned Report No. 517, Loughborough, UK., 121, (2014).

26 Lepper, P. A., Turner, V. L. G., Goodson, A. D., and Black, K. D. Source levels and spectra emitted by three commercial aquaculture anti-predation devices, Proceedings of the Seventh European conference on Underwater Acoustics, ECUA, Delft, The Netherlands, 5-8th July, (2004).

27 Liu, B., Chen, H., Lei, X., Ren, F., and Sezaki, $\mathrm{K}$. Internode distance-based redundancy reliable transport in underwater sensor networks, EURASIP Journal of Wireless Communications and Networking, 16, (2010). https://dx.doi.org/10.1155/2010/358071

28 López, B. D., and Mariño, F. A trial of acoustic harassment device efficacy on free-ranging bottlenose dolphins in Sardinia, Italy, Marine and Freshwater Behaviour and Physiology, 44, 197-208, (2011). https://dx.doi.org/10.1080/10236244.2011.618216

29 Madsen, P. T. Marine mammals and noise: Problems with root mean square sound pressure levels for transients, Journal of the Acoustical Society of America, 117, 3952-3957, (2005). https://dx.doi.org/10.1121/1.1921508

30 Morton, A. B., and Symonds, H. K. Displacement of Orcinus orca (L.) by high amplitude sound in British Columbia, Canada, ICES Journal of Marine Science, 59, 71-80, (2002). https://dx.doi.org/10.1006/jmsc.2001.1136

31 Nedwell, J. R., Edwards, B., Turnpenny, A. W. H., and Gordon, J. Fish and Marine Mammal Audiograms: A summary of available information, Subacoustech, 281, (2004).

32 Northridge, S., Coram, A., and Gordon, J. Investigations on seal depredation at Scottish fish farms, Scottish Government, Edinburgh, 79, (2013).

33 Northridge, S. P., Fortuna, C. M., and Read, A. Guidelines for technical measures to minimise cetacean-fishery conflicts in the Mediterranean and Black Seas. Agreement on the Conservation of Cetaceans in the Black Sea, Mediterranean Sea and contiguous Atlantic area (ACCOBAMS) Secretariat, Doc 28 annexed to Resolution 2.12 and adopted by the ACCOBAMS MOP. ACCOBAMS Secretariat, Monaco, (2006). 
${ }^{34}$ Northridge, S. P., Gordon, J. G., Booth, C., Calderan, S., Cargill, A., Coram, A., Gillespie, D., Lonergan, M., and Webb, A. Assessment of the impacts and utility of acoustic deterrent devices, Sea Mammal Research Unit, Scottish Oceans Institute, University of St Andrews, and Ecologic, (2010)

35 Nowacek, D. P., Thorne, L. H., Johnston, D. W., and Tyack, P. L. Responses of cetaceans to anthropogenic noise, Mammal Review, 37, 81-115, (2007). https://dx.doi.org/10.1111/j.1365-2907.2007.00104.x

36 Olesiuk, P. F., Nichol, L. M., Sowden, M. J., and Ford, J. K. B. Effect of the sound generated by an acoustic harassment device on the relative abundance and distribution of harbor porpoises (Phocoena phocoena) in retreat passage, British Columbia, Marine Mammal Science, 18, 843-862, (2002). https://dx.doi.org/10.1111/j.1748-7692.2002.tb01077.x

${ }^{37}$ Porter, M. B. The BELLHOP Manual and User's Guide: PRELIMINARY DRAFT. January 31, 2011. Heat, Light, and Sound Research, Inc., La Jolla, CA, USA., 57, (2011).

38 Porter, M. B., and Bucker, H. P. Gaussian beam tracing for computing ocean acoustic fields, The Journal of the Acoustical Society of America, 82, 1349-1359, (1987). https://dx.doi.org/10.1121/1.395269

39 Reeves, R. R., Hofman, R. J., Silber, G. K., and Wilkinson, D. Acoustic Deterrence of Harmful Marine MammalFishery Interactions, National Marine Fisheries Service, 68, (1996).

40 Reeves, R. R., Read, A. J., and Notobartolo di Sciara, G. Report of the workshop on interactions between dolphins and fisheries in the Mediterranean: evaluation of mitigation alternatives, Unpublished report to the International Whaling Commission Scientific Committee. May 2001, Rome, Italy, Cambridge, (2001).

${ }^{41}$ Richardson, W. J., Greene, C. R. J., Malme, C. I., and Thomson, D. H. Marine mammals and noise. Academic Press, San Diego, California, USA, (1995).

42 Robertson, F. C. The effects of acoustic deterrent devices on harbour porpoise (phocoena phocoena) and seals in the vicinity of fish farms in the Orkneys, Scotland, MRes Marine and Fisheries Science, University of Aberdeen, (2004).

43 Shapiro, A. D., Tougaard, J., Jørgensen, P. B., Kyhn, L. A., Balle, J. D., Bernardez, C., Fjälling, A., Karlsen, J., and Wahlberg, M. Transmission loss patterns from acoustic harassment and deterrent devices do not always follow geometrical spreading predictions, Marine Mammal Science, 25, 53-67, (2009). https://dx.doi.org/10.1111/j.17487692.2008.00243.x

${ }^{44}$ Southall, B. L., Bowles, A. E., Ellison, W. T., Finneran, J. J., Gentry, R. L., Greene, C. R., Kastak, D., Ketten, D. R., Miller, J. H., Nachtigall, P. E., Richardson, W. J., Thomas, J. A., and Tyack, P. L. Marine mammal noise exposure criteria, initial scientific recommendations, Aquatic Mammals, 33, 411-414, (2007). https://dx.doi.org/10.1080/09524622.2008.9753846

45 Terhune, J. M., Hoover, C. L., and Jacobs, S. R. Potential detection and deterrence ranges by harbor seals of underwater acoustic harassment devices (AHD) in the Bay of Fundy, Canada, Journal of the World Aquaculture Society, 33, 176-183, (2002). https://dx.doi.org/10.1111/j.17497345.2002.tb00492.x

46 Tixier, P., Gasco, N., Duhamel, G., and Guinet, C. Habituation to an acoustic harassment device (AHD) by killer whales depredating demersal longlines, ICES Journal of Marine Science, 71, 9, (2014). https://dx.doi.org/10.1093/icesjms/fsu166

47 Tixier, P., Gasco, N., Duhamel, G., and Guinet., C. Themed Section: 'Marine Mammal Bycatch and Depredation'. Habituation to an acoustic harassment device (AHD) by killer whales depredating demersal longlines. (Orcinus orca), ICES Journal of Marine Science, 72, 1673-1681, (2015). https://dx.doi.org/10.1093/icesjms/fsu166

48 Todd, V. L. G., Todd, I. B., Gardiner, J. C., and Morrin, E. C. N. Marine Mammal Observer and Passive Acoustic Monitoring Handbook, Pelagic Publishing Ltd, Exeter, UK., (2015).

49 Vilata, J., Oliva, D., and Sepúlveda, M. The predation of farmed salmon by South American sea lions (Otaria flavescens) in southern Chile, ICES Journal of Marine Science: Journal du Conseil, 67, 475-482, (2010). https://dx.doi.org/10.1093/icesjms/fsp250

50 Webb, S. The equilibrium oceanic microseism spectrum, Journal of the Acoustical Society of America, 92, 21412158, (1992). https://dx.doi.org/10.1121/1.405226

51 Wright, A. J., Aguilar Soto, N., Baldwin, A. L., Bateson, M., Beale, C. M., Clark, C., Deak, T., Edwards, E. F., Fernandez, A., Godinho, A., Hatch, L. T., Kakuschke, A., Lusseau, D., Martineau, D., Romero, L. M., Weilgart, L. S., Wintle, B. A., Notarbartolo-di-Sciara, G., and Martin, V. Do marine mammals experience stress related to anthropogenic noise? International Journal of Comparative Psychology, 20, 274-316, (2007).

52 Yang, H., Liu, B., Ren, F., Wen, H., and Lin, C. Optimization of energy efficient transmission in underwater sensor networks, GLOBECOM 2009 - 2009 IEEE Global Telecommunications Conference, Honolulu, HI, 1-6, (2009). https://dx.doi.org/10.1109/GLOCOM.2009.5425484

53 Yurk, H., and Trites, A. W. Experimental attempts to reduce predation by harbor seals on out-migrating juvenile salmonids, Transactions of the American Fisheries Society, 129, 1360-1366, (2000). https://dx.doi.org/10.1577/1548$8659(2000) 129<1360:$ EATRPB $>2.0 . \mathrm{CO} ; 2$ 